\title{
A novel sorbent tube for ambient hydrogen sulfide determination
}

\author{
Mürvet Volkan ${ }^{\text {a,*}}$, Tijen Eroğlu a, Ahmet E. Eroğlu a , O. Yavuz Ataman a, \\ Harry B. Mark Jr. ${ }^{\text {b }}$ \\ a Department of Chemistry, Middle East Technical University, 06531 Ankara, Turkey \\ b Department of Chemistry, University of Cincinnati, Cincinnati, OH 45221, USA
}

Received 4 August 1997; received in revised form 16 February 1998; accepted 20 February 1998

\begin{abstract}
A novel tubular device has been developed for hydrogen sulfide determination in air. Several substrates such as commercial silica gel and alumina TLC plates, silica gel powder, alumina, $\mathrm{CaSO}_{4}, \mathrm{CaCO}_{3}, \mathrm{BaSO}_{4}, \mathrm{MgO}$, chalk, $\alpha$-cellulose and ethyl cellulose were tested as solid substrates. 30-70-mesh silica gel was finally employed in glass tubes of $4.0 \mathrm{~mm}$ internal diameter. Silica gel is treated with $0.5 \mathrm{M}$ aqueous $\mathrm{CdCl}_{2}$ solution, dried, filled into the glass tube and sample gas is passed through the device using nitrogen as the carrier gas where $70 \%$ relative humidity is employed. The analyte reacts with the solid substrate to form a luminescent spot whose length in the tube is measured and correlated to concentration. The flow rate was $68 \mathrm{ml} \mathrm{min}{ }^{-1}$. The analytical system is linear in the range of $0.2-1.3 \mathrm{ppm} \mathrm{H}_{2} \mathrm{~S}$ for the specified conditions. The prepared devices are stable at least for 3 months prior to sampling; and after sampling, the luminescing spot is stable also at least for 3 months. C 1998 Elsevier Science B.V. All rights reserved.
\end{abstract}

Keywords: Hydrogen sulfide; Room temperature luminescence; Air pollution control

\section{Introduction}

Hydrogen sulfide is produced in nature primarily by decomposition of organic materials by bacteria. In addition, it is a constituent of natural gas, petroleum, sulfur deposits, volcanic gases and sulfur springs. The exposure limit value recommended by NIOSH (United States National Institute for Occupational Safety and Health) is 10

\footnotetext{
* Corresponding author. Tel.: +90312 2103228; fax: +90 312 2101280; e-mail: murvet@rorqual.cc.metu.edu.tr
}

$\mathrm{ppm} / 10 \mathrm{~min}$. The immediately dangerous to life or health (IDLH) level is $300 \mathrm{ppm}$. Olfactory sensation is lost at $150-200 \mathrm{ppm}$ where the unpleasant odor of rotten eggs ceases to be an insufficient warning for lethal exposure. Although the concentration of hydrogen sulfide in ambient air is not commonly so high to cause any health effects, it is necessary to monitor its concentration in certain locations since the presence of this gas has been one of the possible causes of casualties among people who work in sewers and similar environments. The most widely used fundamental tech- 
niques for $\mathrm{H}_{2} \mathrm{~S}$ determination have been compared by Bethea [1]. The chemical methods include collection of gas in liquid [2-4], collection on impregnated solid substrates [5-7], coulometry $[8,9]$, gas chromatography [10-13] and ion chromatography [14].

This paper describes the development of a simple, low cost and sensitive method for the determination of $\mathrm{H}_{2} \mathrm{~S}$ concentration in air. The procedure has been developed by exploiting the room temperature luminescence signal obtained from the reaction of $\mathrm{CdCl}_{2}$ with ambient $\mathrm{H}_{2} \mathrm{~S}$. A $\mathrm{CdCl}_{2}$-treated silica gel column was utilized as a dosimeter with proper calibration. The concentration of the analyte in air was simply correlated to the length of the tubular device which exhibits luminescence.

\section{Experimental}

\subsection{Instrumentation}

All the luminescence spectra were obtained by using a Perkin-Elmer Model LS50B Luminescence Spectrometer equipped with a $150-\mathrm{W}$ xenon lamp as excitation source. A yellow cut-off optical filter was placed before the entrance slit of the emission monochromator. This spectrometer was used to characterize the luminescence spectra on different substrates. The final analytical measurements for the tubular device developed in this study relies on visual examination only. Standard gas concentrations were obtained by a Vici Metronics Dynacalibrator Model 230-14-C gas dilution system using permeation tubes obtained from the same company. Permeation tubes were used as needed, for both analyte and the interferant gases. In all the preparations, the permeation tube chamber temperature was set to $30^{\circ} \mathrm{C}$ for use and the calibration of the permeation tubes was done by measuring the weight loss versus time. $\mathrm{N}_{2}$ was used as the carrier and dilution gas. The relative humidity was adjusted by mixing the analyte gas stream with a controlled humidity gas stream; the final relative humidity was determined by the relative amounts of the two streams. A humidity measuring box-type device (Fisher Scientific) was placed in the reaction chamber and its display was directly viewed through the transparent window of the chamber. The carrier gas stream with the desired humidity was obtained by using a washing bottle containing a saturated salt solution; $\mathrm{Pb}\left(\mathrm{NO}_{3}\right)_{2}$ was used to provide a final relative humidity of $70-74 \%$ in the reaction chamber.

\subsection{Preparation of solid substrates by $\mathrm{CdCl}_{2}$ treatment}

Commercial silica gel and alumina TLC plates, silica gel powder, alumina, $\mathrm{CaSO}_{4}, \mathrm{CaCO}_{3}$, $\mathrm{BaSO}_{4}, \mathrm{MgO}$, chalk, $\alpha$-cellulose and ethyl cellulose were tested as solid substrates. Approximately $0.5 \mathrm{~g}$ of the solid substrate material were immersed into $0.5 \mathrm{M}$ aqueous solution of $\mathrm{CdCl}_{2}$ and the contents were mixed well. After waiting for $5 \mathrm{~min}$, the mixtures were filtered through a filter paper and the solid part was dried in an oven at $80^{\circ} \mathrm{C}$. Since $\mathrm{CdCl}_{2}$ is toxic, its handling was always carried out under a well-ventilated hood with extra care.

\subsection{Measurements for luminescence characterization of the solid substrates}

By using an IR pellet preparation kit, the solid materials which remained on the filter paper were pelletized and placed in the reaction chamber which has been described previously [7]. The luminescence signals on these solid substrates were then measured by the luminescence spectrometer utilizing a solid surface accessory.

\subsection{Preparation and calibration of $\mathrm{H}_{2} \mathrm{~S}$ dosimeter}

Silica gel, 30-70 mesh, which was treated by $\mathrm{CdCl}_{2}$ as described above, was filled into a glass tube having an internal diameter of $4.0 \mathrm{~mm}$ and a length of $8.0 \mathrm{~cm}$. The front end of this tubular device was connected to the output of the Vici Metronics system; the other end was connected to the exhaust. The flow rate of the sampling gas, 68 $\mathrm{ml} \mathrm{min}^{-1}$, and relative humidity, $70 \%$, were kept constant throughout the calibration measurements. After exposure to the analyte gas for a measured duration and under controlled condi- 
tions, the tubes were removed from the sampling system and placed in a dark location. For this purpose, a dark room or any place with subdued light may be used, but a simple box made from cardboard would also be sufficient. The tubes were illuminated under a portable UV lamp, Camag 29000. The length of the column that fluoresces was measured. Duplicate measurements were carried out for each concentration value.

\section{Results and discussion}

It was previously demonstrated that atmospheric hydrogen sulfide reacts with the surface of a filter paper treated with aqueous $\mathrm{CdCl}_{2}$ and yields a luminescent species whose intensity can be correlated with the analyte concentration in ambient air [7]. It has also been shown that the luminescent species is CdS solid particles which were formed in a well-defined size [7]. In this study, the similar principles were employed for signal formation using a tubular device which is familiar to most users for monitoring toxic gases in a rapid, simple and inexpensive way.

\subsection{Selection of the column material}

In the literature [15-19], a variety of solid materials has been tested in room temperature luminescence (RTL) studies, and it has been concluded that one should select the most convenient substrate by considering the specific purpose of the determination, since no clear-cut guidelines could be developed. In the previous study [7], filter paper was chosen because of its low cost and high performance as a substrate. In this study, in order to make the measurements in a tubular device, a material consisting of particles of well-defined mesh size was sought for, so that it can be easily and conveniently filled into a glass tube. Some commercial TLC plates, in addition to the pellets prepared from various materials, were tried. The results are given in Table 1 and some typical background and sample fluorescence spectra obtained from these substrates are presented in Figs. 1-3. In these figures, the spectral features in the range of $350-500 \mathrm{~nm}$ are common to all the spectra; these peaks are the result of surface scattering of the Xe lamp emission. A cut-off filter of about $50 \%$ transmittance at $350 \mathrm{~nm}$ was used to prevent the background peak at $600 \mathrm{~nm}$ due to the scattering of excitation beam as the second order. As it can easily be understood from the table and the figures, the most satisfactory signal was obtained on the surface of the silica gel TLC plate. The relatively high homogeneity of the commercial silica gel TLC plate can be seen in Fig. 4. The silica gel was preferred as the column material because of its relatively high sensitivity and high signal/background value. Therefore, 30-70 mesh size silica gel was used as a column material; this material can be easily filled into the column and allows a large range of flow rates while the gas is sampled.

Table 1

Luminescence signals obtained on various substrates

\begin{tabular}{|c|c|c|c|}
\hline Substrate $^{\mathrm{a}}$ & Relative signal $^{\mathrm{b}}$ & RSD $(\%)$ & $(\mathrm{S} / \mathrm{B})^{\mathrm{c}}$ \\
\hline $\mathrm{CaSO}_{4}$ & $58 \pm 5$ & 9 & 0.58 \\
\hline Chalk (dirty) & $57 \pm 3$ & 5 & 0.57 \\
\hline Chalk (white) & $73 \pm 6$ & 8 & 0.73 \\
\hline $\mathrm{BaSO}_{4}$ & $85 \pm 20$ & 24 & 0.85 \\
\hline $\begin{array}{l}\text { Silica gel 60G } \\
\text { (for TLC) }\end{array}$ & $97 \pm 26^{\mathrm{d}}$ & 27 & 0.97 \\
\hline $\begin{array}{l}\mathrm{Al}_{2} \mathrm{O}_{3} \text { (for } \\
\text { column chrom.) }\end{array}$ & $80 \pm 14^{d}$ & 18 & 0.80 \\
\hline $\mathrm{Al}_{2} \mathrm{O}_{3}$ (for TLC) & $45 \pm 18$ & 40 & 0.45 \\
\hline $\mathrm{MgO}$ & $20 \pm 3$ & 15 & 0.20 \\
\hline $\mathrm{CaCO}_{3}$ & $43 \pm 18$ & 42 & 0.43 \\
\hline$\alpha$-Cellulose & $28 \pm 5$ & 18 & 0.28 \\
\hline Ethyl cellulose & $24 \pm 7$ & 29 & 0.24 \\
\hline $\begin{array}{l}\text { Acetylated } \\
\text { cellulose }^{\mathrm{e}}\end{array}$ & $104 \pm 17^{\mathrm{f}}$ & 16 & 1.04 \\
\hline Silica gel $^{\mathrm{e}}$ & $164 \pm 10$ & 6 & 1.64 \\
\hline
\end{tabular}

Treatment solution, $0.5 \mathrm{M} \mathrm{CdCl}_{2} ; 0.870 \mathrm{ppm} \mathrm{H}_{2} \mathrm{~S} ; 60 \mathrm{~min}$

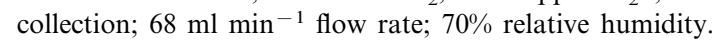

${ }^{a}$ Pelletized with an IR pellet preparation kit.

${ }^{\mathrm{b}}$ Mean of five measurements \pm standard deviations.

${ }^{\mathrm{c}}$ Ratios of analyte signal at $620 \mathrm{~nm}$ to the background signal at $423 \mathrm{~nm}$.

d Analyte signal was measured at $630 \mathrm{~nm}$.

${ }^{\mathrm{e}}$ Commercial TLC plates.

${ }^{\mathrm{f}}$ Analyte signal was measured at $525 \mathrm{~nm}$. 


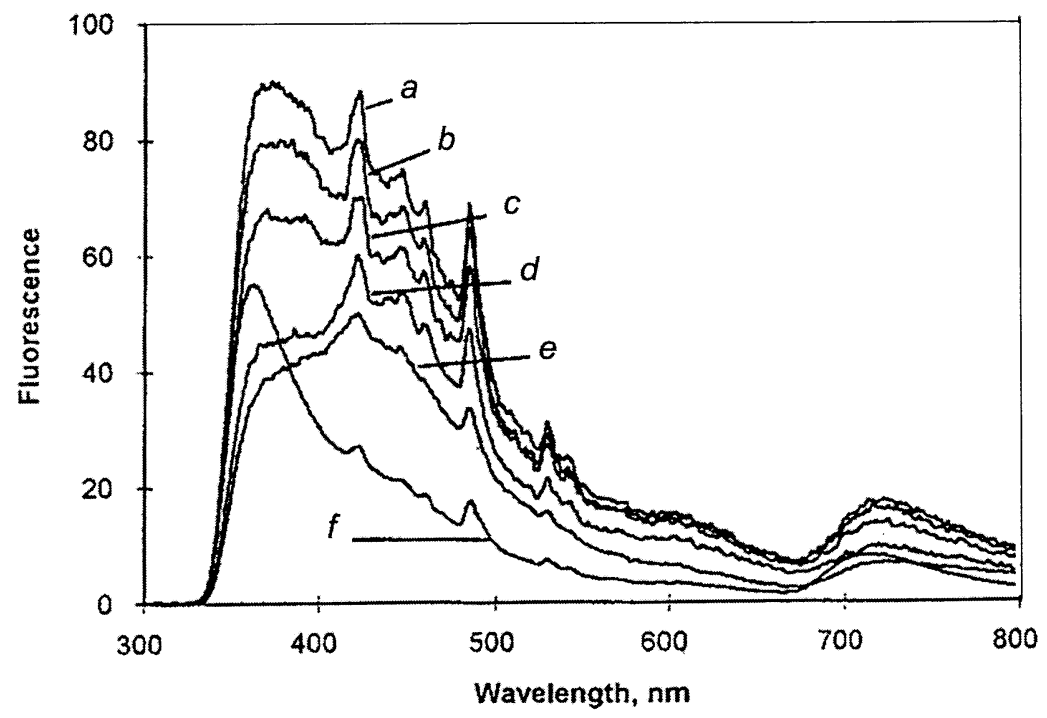

Fig. 1. Background signals from various solid surfaces. $\lambda_{\mathrm{ex}}=300 \mathrm{~nm}$. Slits are 10 and $5 \mathrm{~nm}$ for excitation and emission monochromators, respectively. (a) Silica gel TLC plate; (b) $\mathrm{CaCO}_{3}$; (c) white chalk; (d) gray chalk; (e) ethyl cellulose; (f) nylon filter.

\subsection{Variables affecting the luminescence signal}

The concentration of $\mathrm{CdCl}_{2}$ solution used for treatment of the solid substrate, and the relative humidity of the sampled gas are important parameters. Since they have been studied extensively in the previous paper [7], the optimum values obtained as $0.5 \mathrm{M} \mathrm{CdCl}_{2}$ and $70 \%$ relative humidity were used throughout this study. It should be stressed that, although the presence of humidity is useful for sampling the gas, the normal laboratory temperature and ambient humidity could be employed during the visual examination and the length of the luminescent part is practically not affected by these parameters once it has been formed.

A careful interference study was undertaken; the details are shown in Table 2. These gases were chosen as interferants; because, except $\mathrm{NO}_{2}$, they are the species expected to be found in the environments where $\mathrm{H}_{2} \mathrm{~S}$ is present. The effects of $\mathrm{SO}_{2}$ and methyl mercaptan were explored in more detail since these gases have been known as the major interferants; both their concentrations and the ratio of interferant/analyte concentration were varied. In an initial set of experiments, the interferant gases, in concentrations as described in
Table 2, were sent to the reaction chamber in the absence of analyte; no detectable signals were obtained. In the second set of experiments, the interferant and analyte were used together and the signals obtained were compared to those obtained by $\mathrm{H}_{2} \mathrm{~S}$ alone at the same concentration values; no significant differences were found. In another experiment, the total interference effect of some interferants was tested; 0.114 ppm methyl mercaptan, $0.289 \mathrm{ppm}$ ethyl mercaptan and $0.090 \mathrm{ppm}$ propyl mercaptan were sent to the reaction chamber without any analyte; no detectable signal was obtained. When exactly the same combination of interferants were tested together with $0.654 \mathrm{ppm}$ $\mathrm{H}_{2} \mathrm{~S}$, the signal obtained had no significant difference from that obtained by analyte alone at the mentioned concentration. A 95\% confidence limit was employed for the significance tests. It can be concluded that the sampling procedure is free of interferences, at least for the most commonly known interferants at the mentioned conditions.

\subsection{Monitoring $\mathrm{H}_{2} \mathrm{~S}$ concentrations in air}

The $\mathrm{H}_{2} \mathrm{~S}$ dosimeter developed consists of a small glass tube filled with 30-70-mesh silica gel treated by $\mathrm{CdCl}_{2}$, to be placed in a stationary 


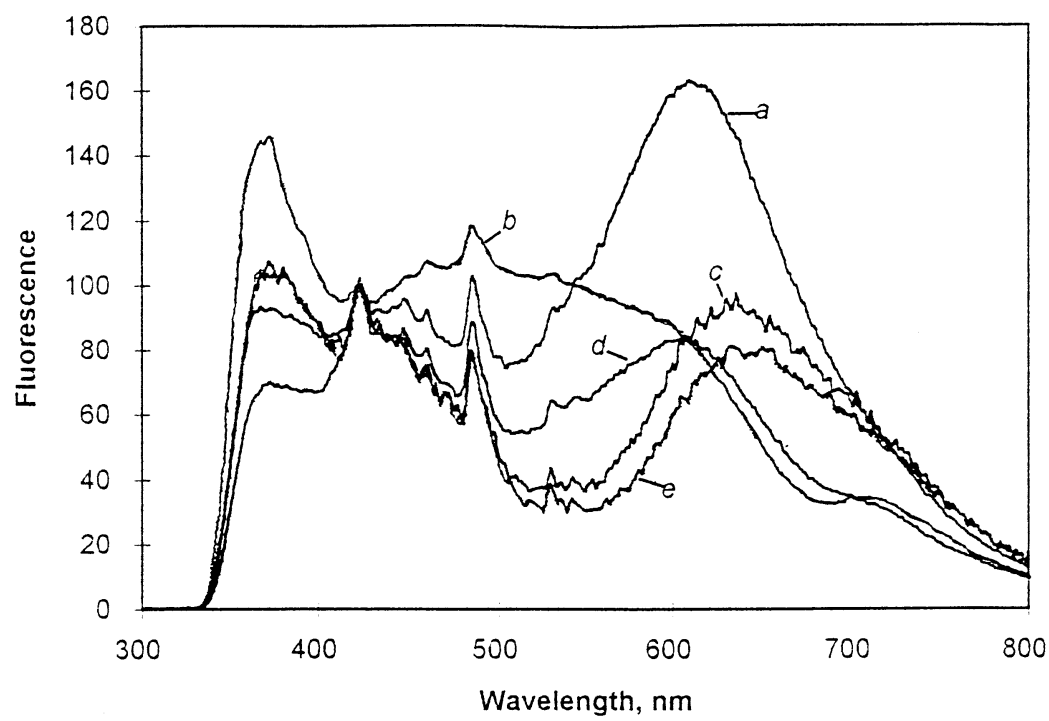

Fig. 2. Fluorescence emission spectra on various surfaces. $\lambda_{\mathrm{ex}}=300 \mathrm{~nm}$. Slits are 10 and $5 \mathrm{~nm}$ for excitation and emission monochromators, respectively. $0.870 \mathrm{ppm} \mathrm{H}_{2} \mathrm{~S}$ was collected for $1 \mathrm{~h}$ at $30^{\circ} \mathrm{C}$ and a relative humidity of $70 \%$. All the spectra were normalized to a relative intensity of 100 at $423 \mathrm{~nm}$. (a) Silica gel TLC plate; (b) acetylated cellulose TLC plate; (c) silica gel (pelletized); (d) cellulose acetate filter; (e) alumina (pelletized)

location for area monitoring. The monitoring procedure is based on the interaction of $\mathrm{H}_{2} \mathrm{~S}$ present in air of the working environment which is sampled through the tubular device.

The flow rate of the sampling system should be adjusted depending on analyte concentration. After exposure to analyte stream, the tube is illuminated by a portable UV source. At this stage, any blacklight source commonly used to view thinlayer chromatography plates can be employed. As can be seen in Figs. 2 and 3, the emission peak is located at around $600 \mathrm{~nm}$; therefore the visual examination of the luminescence is possible. However, the visual examination is very difficult under daylight or in a well-illuminated room. Therefore, the measurement of the length of the column section which luminesces should best be done in a dark place or under subdued light. The concentration or absolute amounts of $\mathrm{H}_{2} \mathrm{~S}$ can be found from the calibration plot. The parameters such as the physical dimensions of the tube, particle size for silica gel, flow rate of sampling and humidity should be kept constant for calibration and measurement. The tubular dosimeter is a direct reading device, which reduces the total analysis time to a duration practically equal to that of sampling.

\subsection{Calibration plots, reproducibility and detection limit}

A typical calibration plot is shown in Fig. 5, where, after a linear response region, the saturation of the dosimeter at high analyte concentrations is illustrated. In this calibration graph, 1.00 ppm corresponds to $5.6 \mu \mathrm{g}$ of $\mathrm{H}_{2} \mathrm{~S}$ collected in the tubular device for the conditions given. Under the same conditions, $1.00 \mathrm{ppm}$ ambient concentration of $\mathrm{H}_{2} \mathrm{~S}$ can also be given as $1.37 \mathrm{mg} \mathrm{m}^{-3} ; 1.00$ ppm $\mathrm{H}_{2} \mathrm{~S}$ corresponds to $1.00 \mathrm{ml}$ of $\mathrm{H}_{2} \mathrm{~S}$ in $1.00 \times$ $10^{6} \mathrm{ml}$ or $1.00 \mathrm{~m}^{3}$ of total gas. Using the ideal gas law at $303 \mathrm{~K}\left(30^{\circ} \mathrm{C}\right)$, it can be shown that $\mathrm{H}_{2} \mathrm{~S}$ ( $34.01 \mathrm{~g} \mathrm{~mol}^{-1}$ ) concentration is equal to $1.37 \mathrm{mg}$ $\mathrm{m}^{-3}$. The duplicate set of tubular devices employed for the linear portion of calibration is shown in Fig. 6; the reproducibility among the duplicate samples are also illustrated in this figure. The photographs were taken in a dark room trying several exposure times for the camera in order to obtain the most realistic photographs. 


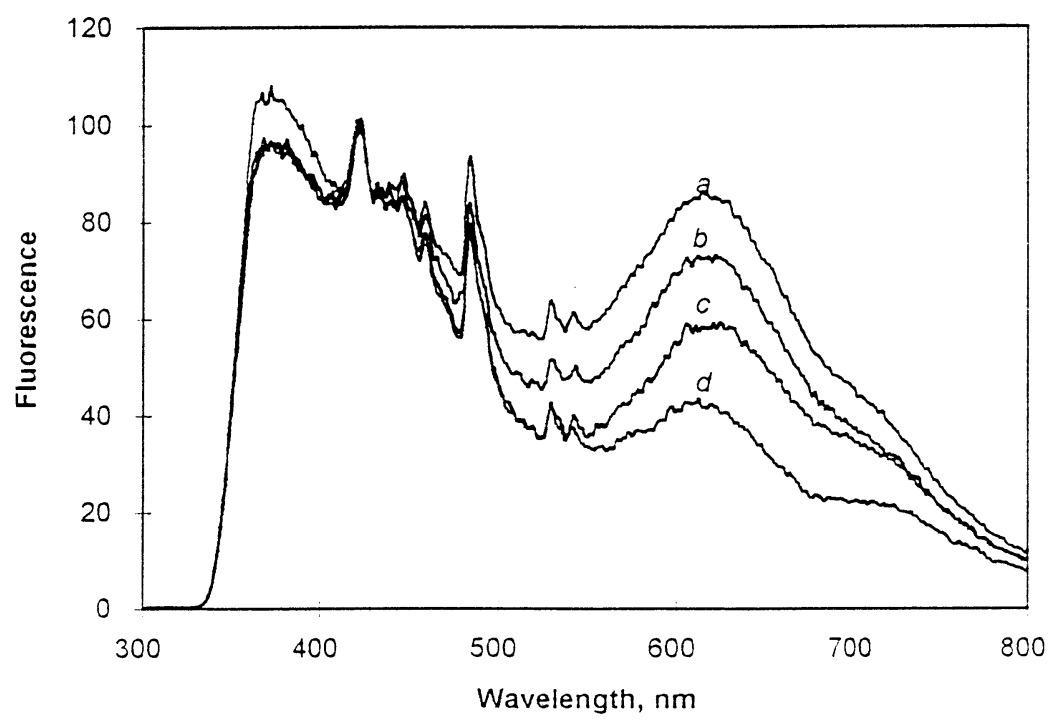

Fig. 3. Fluorescence emission spectra on various pelletized surfaces. $\lambda_{\mathrm{ex}}=300 \mathrm{~nm}$. Slits are 10 and $5 \mathrm{~nm}$ for excitation and emission monochromators, respectively. $0.870 \mathrm{ppm} \mathrm{H}_{2} \mathrm{~S}$ was collected for $1 \mathrm{~h} \mathrm{at} 30^{\circ} \mathrm{C}$ and a relative humidity of $70 \%$. All the spectra were normalized to a relative intensity of 100 at $423 \mathrm{~nm}$. (a) $\mathrm{BaSO}_{4}$; (b) chalk; (c) $\mathrm{CaSO}_{4}$; (d) $\mathrm{CaCO}_{3}$.

The tubes in couples correspond to the points on the calibration plot; two couples (four tubes) are shown for $1.30 \mathrm{ppm} \mathrm{H}_{2} \mathrm{~S}$ to show the typical reproducibility, which was $5.7 \%$ relative standard

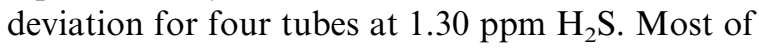
the random error was caused by the physical disruption of the margins of the colored part when the tubes were removed from the chamber. The part which fluoresced was therefore measured by rotat-

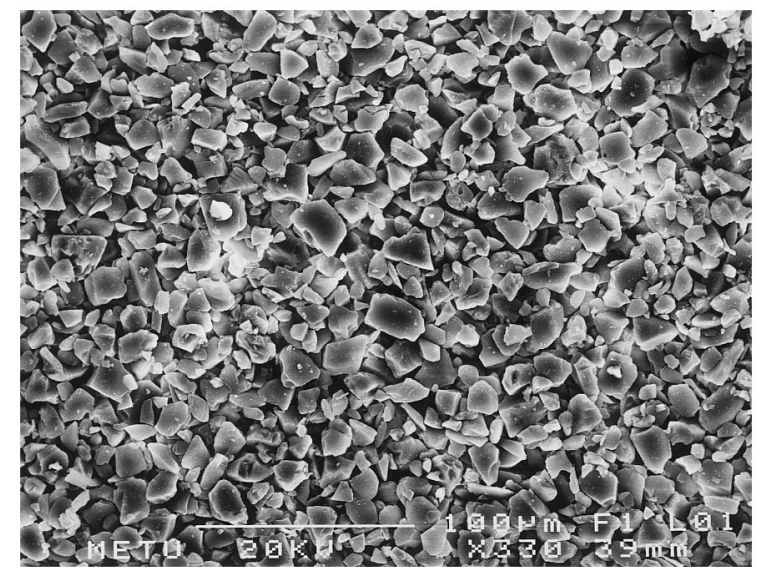

Fig. 4. SEM photograph $(\times 330)$ of commercial silica gel plate surface treated with $0.5 \mathrm{M} \mathrm{CdCl}_{2}$ and exposed to $0.870 \mathrm{ppm}$ $\mathrm{H}_{2} \mathrm{~S}$ for 60 min. ing the tube and recording the height at every $90^{\circ}$ rotation; four measurements were averaged. The standard deviation was $0.06 \mathrm{~cm}$ corresponding to $20 \%$ relative standard deviation for $0.203 \mathrm{ppm}$. A $2 \mathrm{~s}$ detection limit of $0.08 \mathrm{ppm}_{2} \mathrm{~S}$ was found which was based on these measurements.

\section{Conclusion}

The advantages of the tubular device developed in this study may be summarized as follows:

Table 2

Compositions used in interference studies

\begin{tabular}{lll}
\hline Case no. & Interferant gas (ppm) & $\mathrm{H}_{2} \mathrm{~S}(\mathrm{ppm})$ \\
\hline 1 & $\mathrm{SO}_{2}, 0.302$ & 0.677 \\
2 & $\mathrm{SO}_{2}, 0.460$ & 0.064 \\
3 & $\mathrm{CH}_{3} \mathrm{SH}$ (methyl mercaptan), & 0.679 \\
& 0.119 & \\
4 & $\mathrm{CH}_{3} \mathrm{SH}$ (methyl mercaptan), & 0.064 \\
& 0.119 & \\
5 & $\mathrm{CH}_{3} \mathrm{SH}$ (methyl mercaptan), & 0.018 \\
& 0.055 \\
6 & $\mathrm{CH}_{3} \mathrm{CH}$ (ethyl mercaptan), 0.161 & 0.679 \\
7 & $\left(\mathrm{CH}_{3}\right)_{2} \mathrm{~S}$ (dimethyl sulfide), 0.140 & 0.679 \\
8 & $\mathrm{NO}_{2}, 1.95$ & 0.608 \\
\hline
\end{tabular}




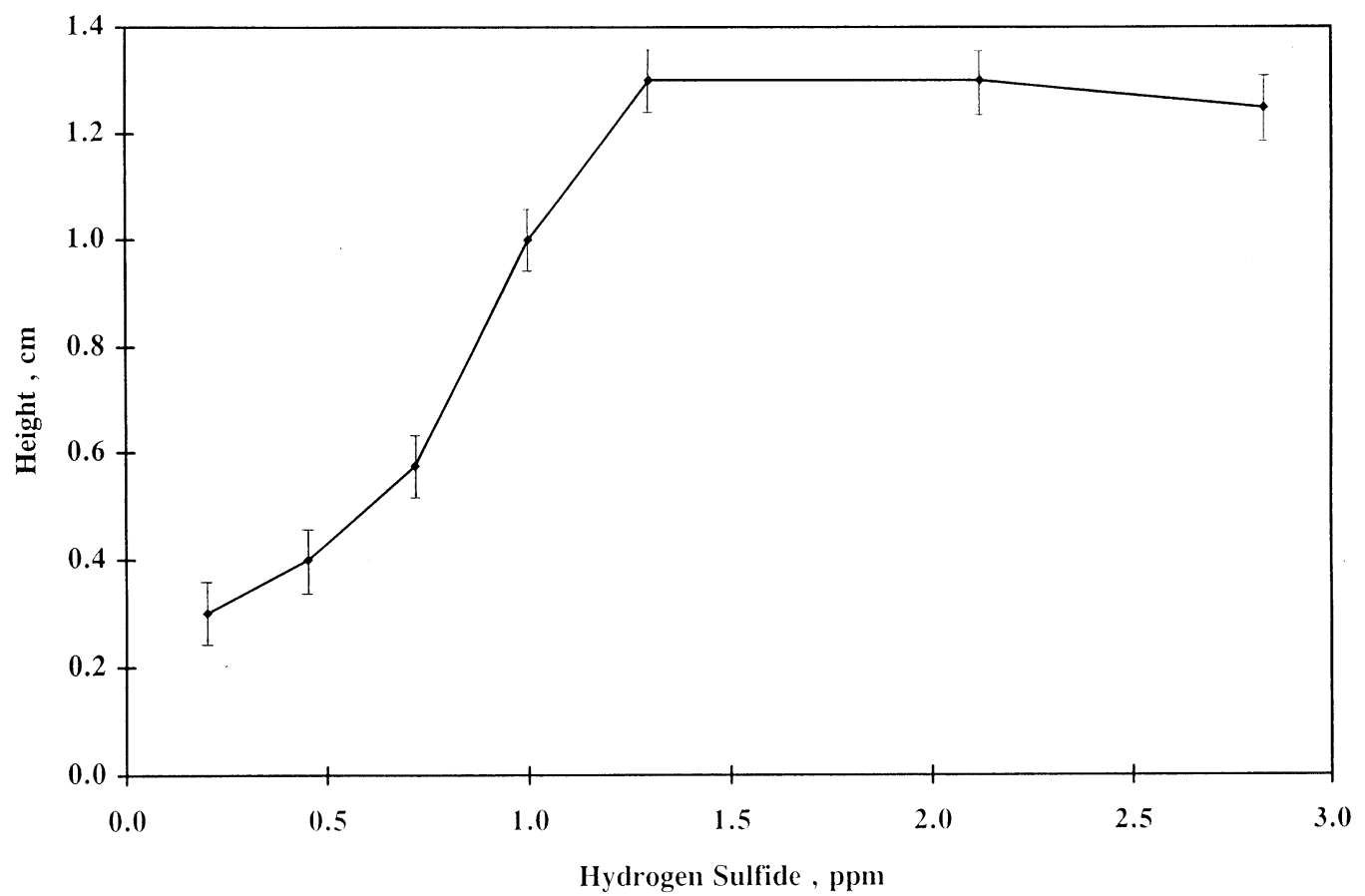

Fig. 5. Calibration plot for tubular devices. Height corresponds to the length of luminescent spot. Flow rate is $68 \mathrm{ml} \mathrm{min}^{-1}, 60 \mathrm{~min}$ sampling.

(1) During the studies done for characterization of the luminescence signals, solid sampling accessory of the luminescence spectrometer was employed and the excitation was performed directly on the solid substrates. Although the excitation wavelengths range between 290 and 350 $\mathrm{nm}$, no quartz tubing was used during the experiments with visual examinations. Apparently, the low-cost glass tubes allow sufficient UV radiation to be transmitted through to induce the visible emission from the surfaces.

(2) The exposure limits, permissible concentrations of airborne contaminants are given as long-term $(8 \mathrm{~h})$ and short-term $(10 \mathrm{~min})$ as well as the time-weighted average (TWA) concentration. This tubular device is suitable for both types of measurements. For short periods, flow rate for sampling should be increased. Once the optimum flow rates are determined, the calibration plot can be prepared accordingly.

(3) The devices can easily be prepared by using a minimum amount of chemicals and time.
Once the tubular devices are prepared, they can be stored for at least 3 months prior to use. It is suggested that a batch of devices be prepared exactly under the same conditions, a number of the tubes should be used to construct the calibration plot where the others can be employed for analyte measurements.

(4) The analytical signal is formed in the tubular device; no extraction or other involved chemical separations are needed.

(5) The examination is done visually, no instrumentation is necessary. A viewing place with subdued light and a portable UV lamp are all needed.

(6) During sampling, the reaction between $\mathrm{H}_{2} \mathrm{~S}$ and $\mathrm{CdCl}_{2}$ is very rapid to form the stable luminescing product. The luminescence of material in the tubes after sampling is very stable and the devices can be stored on a lab bench for at least 3 months once the signal was formed. This may be useful for documentation and/or legal purposes. 


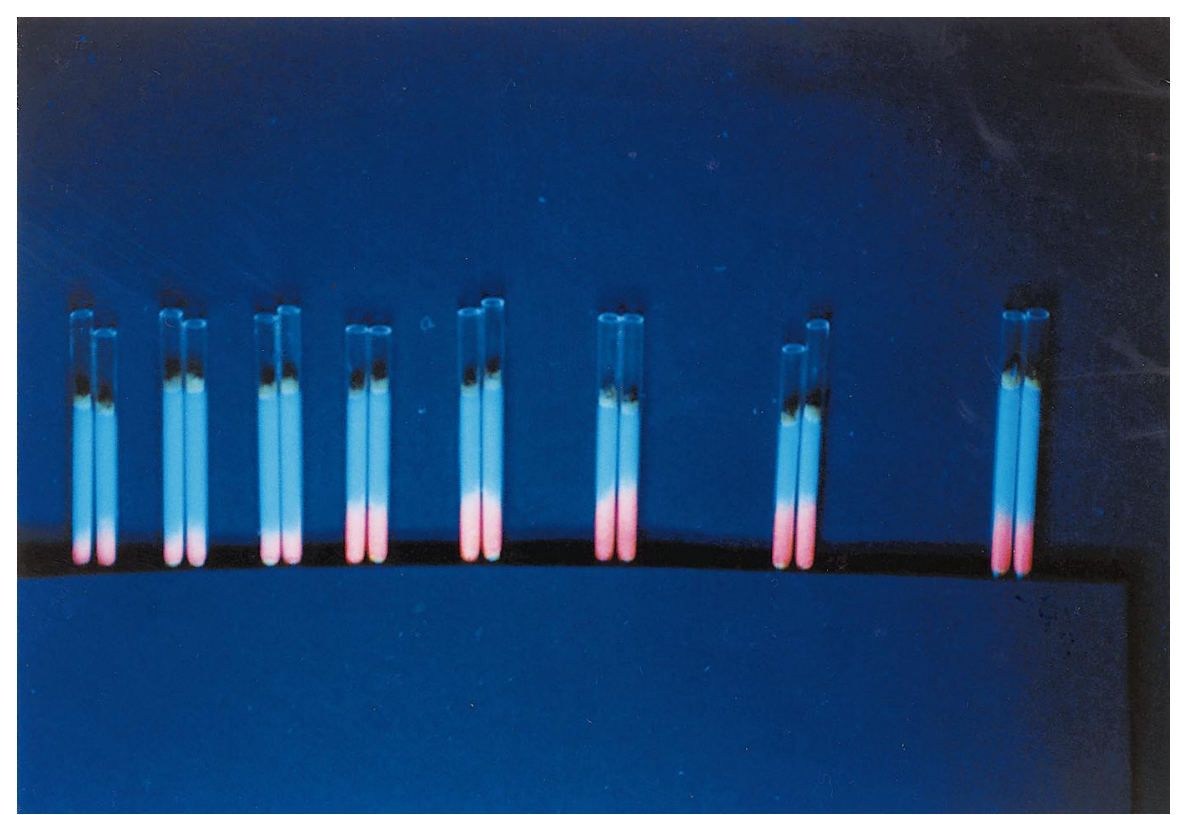

Fig. 6. Photograph of the tubular devices used for the calibration plot given in Fig. 5. From left to right, the tubes in couples correspond to $0.203,0.454,0.720,1.00,1.30,1.30,2.12$ and $2.83 \mathrm{ppm}_{2} \mathrm{~S}$.

(7) For routine purposes, the preparation and the calibration of the tubular devices can be realized in a qualified laboratory. The individual tubular devices can be conveniently marked on the glass surface for several concentration values with well-defined sampling parameters. A good cooperation between the workplace and the laboratory is needed for the assurance of the dosimeter performance.

\section{Acknowledgements}

We would like to acknowledge the financial support by the Middle East Technical University Research Fund through the funds AFP 94-01-0307 and AFP 95-01-03-03 as well as the grant TBAG-1038 by TÜBITAK (The Scientific and Technical Research Council of Turkey).

\section{References}

[1] R.M. Bethea, J. Air Pollut. Control Assoc. 23 (1973) 710 .
[2] M.B. Jacobs, M.M. Braverman, S. Hochheiser, Anal. Chem. 29 (1957) 1349.

[3] T. Pal, A. Ganguly, D.S. Maity, Analyst 111 (1986) 691.

[4] J.T. Purdham, L. Yongyi, Am. Ind. Hyg. Assoc. J. 51 (1990) 269.

[5] R. LaRue, O.Y. Ataman, D.P. Hautman, G. Gerhardt, H. Zimmer, H.B. Mark Jr., Anal. Chem. 59 (1987) 2313.

[6] E.T. Hayes, O.Y. Ataman, A.E. Karagözler, Y.L. Zhang, D.P. Hautman, R.T. Emerich, A.G. Ataman, H. Zimmer, H.B. Mark Jr., Microchem. J. 41 (1990) 98.

[7] A.E. Eroğlu, M. Volkan, E. Bayramlı, O.Y. Ataman, H.B. Mark Jr., Fresenius J. Anal. Chem. 355 (1996) 667.

[8] D.F. Adams, W.L. Bamesberger, T.J. Robertson, J. Air Pollut. Control Assoc. 18 (1968) 145.

[9] W.L. Bamesberger, D.F. Adams, Tappi 52 (1969) 1302.

[10] R.K. Stewens, J.D. Mulik, A.E. O'Keefe, K.J. Krost, Anal. Chem. 38 (1966) 760.

[11] R.S. Braman, J.M. Ammons, J.L. Briker, Anal. Chem. 50 (1978) 992.

[12] F.J. Sandalls, S.A. Penkett, Atmos. Environ. 11 (1977) 197.

[13] S. Jacobsson, O. Falk, J. Chromatogr. 479 (1989) 194.

[14] NIOSH Manual of Analytical Methods, 4th ed., US Department of Health and Human Services, Cincinnati, OH, USA, 1994.

[15] R.J. Hurtubise, in: G.G. Guilbault (Ed.), Solid Surface Luminescence Analysis: Theory, Instrumentation, Appli- 
cations, Modern Monographs in Analytical Chemistry, vol. 1, Marcel Dekker, New York, 1981.

[16] R.J. Hurtubise, Phosphorimetry: Theory, Instrumentation and Applications, VCH, New York, 1990.

[17] R.J. Hurtubise, Molecular luminescence spectroscopy: methods and applications, Part II, in: S.G. Schulman, (Ed.), Chemical Analysis, vol. 77 (J.D. Winefordner (Ed.),
Wiley, New York, 1988.

[18] T. Vo-Dinh, Room temperature phosphorimetry for chemical analysis, in: P.J. Elwing, J.D. Winefordner (Eds.), Chemical Analysis, vol. 68, Wiley, New York, 1984.

[19] M. Gunshefski, J.J. Santana, J. Stephenson, J.D. Winefordner, Appl. Spect. Rev. 27 (1992) 143. 